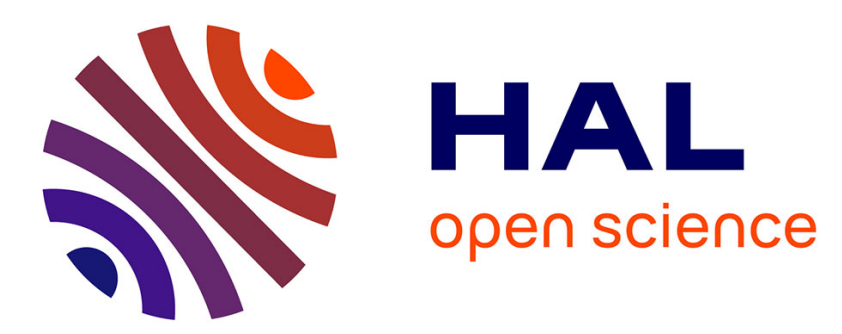

\title{
Numerical modelling of PCB planar inductors: impact of 3D modelling on high-frequency copper loss evaluation
}

Laurent Taylor, Xavier Margueron, Yvonnick Le Menach, Philippe Le Moigne

\section{To cite this version:}

Laurent Taylor, Xavier Margueron, Yvonnick Le Menach, Philippe Le Moigne. Numerical modelling of PCB planar inductors: impact of 3D modelling on high-frequency copper loss evaluation. IET Power Electronics, 2017, 10 (14), pp.1966 - 1974. 10.1049/iet-pel.2017.0086 . hal-01886541

\section{HAL Id: hal-01886541 https://hal.science/hal-01886541}

Submitted on 2 Oct 2018

HAL is a multi-disciplinary open access archive for the deposit and dissemination of scientific research documents, whether they are published or not. The documents may come from teaching and research institutions in France or abroad, or from public or private research centers.
L'archive ouverte pluridisciplinaire $\mathbf{H A L}$, est destinée au dépôt et à la diffusion de documents scientifiques de niveau recherche, publiés ou non, émanant des établissements d'enseignement et de recherche français ou étrangers, des laboratoires publics ou privés. 


\title{
Numerical Modeling of PCB Planar Inductors: Impact of 3D Modeling on High Frequency Copper Loss Evaluation
}

\author{
Laurent Taylor $^{1}$, Xavier Margueron ${ }^{1, *}$, Yvonnick Le Menach ${ }^{1}$, Philippe Le Moigne $^{1}$ \\ ${ }^{1}$ Univ. Lille, Centrale Lille, Arts et Metiers ParisTech, HEI, EA 2697 - L2EP - Laboratoire \\ d'Electrotechnique et d'Electronique de Puissance, F-59000 Lille, France \\ *xavier.margueron@ec-lille.fr
}

\begin{abstract}
Loss values are key parameters for designing high performance high frequency (HF) magnetic components for power electronics (PE) converters. With the increase of PE switching frequencies, copper losses have to be precisely quantified, ideally until some megahertz. In the literature, many 2D numerical simulations based on finite element analysis (FEA) are performed for such computations. 3D FEA studies of planar components are still limited because of modeling problems, computational resources and computing time. In this paper, quantitative comparisons between 2D and 3D simulation results for planar inductors are achieved focusing on copper loss computation. Results are compared in terms of simulation performances and accuracy. The aim of the paper is to highlight benefits of 2D and 3D FEA simulations in order to choose the appropriate model according to the studied problem.
\end{abstract}

\section{Introduction}

High Frequency (HF) planar magnetic components (PMC) are interesting solution for the integration of power electronic converters. Indeed, in comparison with other classical HF wounded components, planar inductors and transformers are low-profile and lead to more power density in smaller and lighter components [1,2]. They are particularly dedicated to embedded devices and transportation systems [1,3], where size and weight are important criterias. The other main advantage, dealing with this technology, is the low dispersion characteristic linked to their fabrication process. The latter also leads to more controllable and predictable parasitic parameters [4]. PMC now can be found in a lot of applications: Resonant converters [5, 6], gate drivers [7], Electromagnetic compatibility (EMC) filters [8,9], high voltage or high current applications [10-13] for example.

From a practical point of view, PMC's windings can be made with multilayer printed circuit board (PCB) or copper foils. Due to these technologies, there are significant differences between its geometrical sizes: height, width and length of copper layers and magnetic core. This singularity enables to obtain components with a really good efficiency but leads to problem when dealing with numerical modeling. Indeed, to simulate resistive and inductive variations in HF, meshing has to be very thin (typically $20 \mu m @ 30 M H z$ ) in order to take into account skin and proximity effects inside conductors. Such problem requires a performing computing code and also important computational resources.

This paper investigates the problem of HF planar component numerical modeling. In the literature, numerous papers present 1D planar modeling [13-16] as well as comparison between ana- 
lytical calculations to 2D numerical computations for copper losses evaluation [17-22]. Although analytical models are precise in low frequency (LF), the error on copper loss calculations strongly increases with frequency and can reach more than $20 \%$ in HF [17]. One of the reasons is linked to the space between conductors that cancel the 1-D hypothesis on the magnetic field, commonly known as the Dowell hypothesis [23]. 2D numerical modeling can then be used to overcome this problem. However, differences still exist while comparing simulation results with measurements on real devices $[17,20]$. The reason is that the 2D models are too simplistic and do not take into account the effect of the third dimension. For some years, 3D modeling of planar components has appeared in the literature $[5,24]$ but such simulations are still limited, especially when dealing with HF current density calculation and copper losses. The implementation of 3-D Finite Element Analysis (FEA) simulations is time-consuming and needs high performance computing resources. Even if computer performances still increase, it can be interesting to answer some questions: With regard to planar component HF copper loss computation, is a 3D modeling really necessary? Is a 2D approach sufficient for designers? What is really lost with such simplification?

In this paper, 2D and 3D FEA are performed on HF planar components to compute HF copper losses. Simulations results are analysed and compared to answer the previous questions. The paper is organized as follows: Section 2 starts with an introduction to HF copper loss numerical computation and problems dealing with the modeling of planar magnetic components. Then, in section 3, 2D and 3D simulations are performed on two types of devices: 2-layer PCB without magnetic core and complete planar inductors, including PCB's windings and ferrite cores. 2$\mathrm{D}$ and 3-D FEA simulation results are precisely analysed to highlight differences between both kinds of FEA simulations. In section 4, impedance measurements are realized on prototypes to be compared to FEA results. Finally, all these comparisons lead to conclude on the benefits, drawbacks and usefulness of 3D modeling for HF planar components.

\section{Problematic of HF Power Electronic Magnetic Component Modeling}

\subsection{Review of $3 D$ Modeling Methods}

In the literature, 2D FEA is widely performed to compute copper losses in magnetic components [17-22]. Such simulations enable to validate hypothesis used in analytical modeling. The study of HF magnetic component in 3D is still limited because of problems linked to modeling complexity, computing resources and calculation times. To avoid these difficulties and simplify the numerical problem, some methods have been developped based on the use of multiple 2D simulations [24,25].

Regarding other numerical modeling method, the Partial Element Equivalent Circuit (PEEC) method [26] enables the computation of PCB without magnetic cores. Each conductor is divided into elementar ones, where the current is considered as uniform. Some equivalent circuits are then obtained for each elementary conductor and connected together. However, this method can not be directly applied for PMC because magnetic material can not be considered. Some extensions have been developped such as the the $\mu$ PEEC method [27] which takes into account magnetic material but only for 2D modeling as well as the PEEC-BIM [28] that can be used for 3D computation but limited to toroidal cores. Recently, FEA and PEEC benefits were combined for the computation of Litz Wire Systems [29]. 


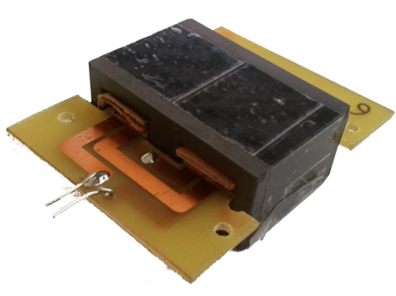

(a)

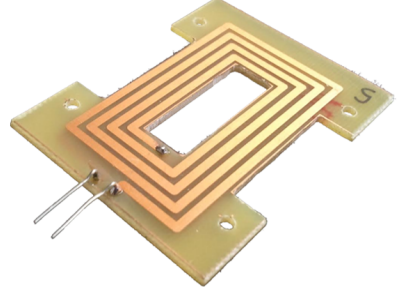

(b)

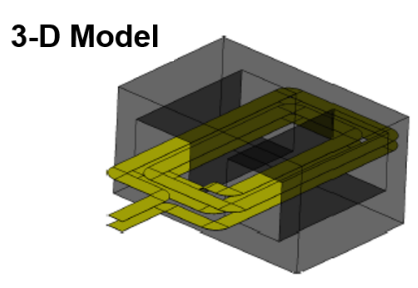

(c)

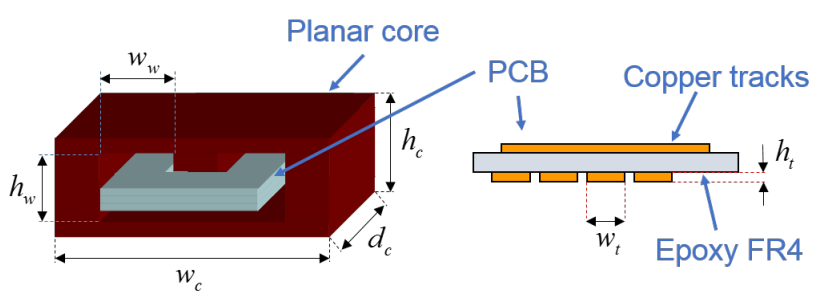

(d)

Fig. 1. Planar component

a Planar inductor

b PCB

c 3D and 2D models

d Typical lengths

\subsection{Planar Component Specificities}

Planar components (Fig.1(a)) are made of flat ferrite magnetic core and PCB windings (Fig.1(b)). Examples of 3D and 2D numerical models of planar components are presented in The Fig.1(c).

The typical lenghts of Ferroxcube [30] planar cores (Fig.1(d)) are listed in Table 1. Copper track thicknesses $h_{t}$ depend on the technology of PCB's manufacturers. Standard values of $h_{t}$ are $35 \mu \mathrm{m}, 70 \mu \mathrm{m}, 105 \mu \mathrm{m}$ or $210 \mu \mathrm{m}$ while $w_{t}$ is a design parameter that can vary up to the length of core's window $w_{w}$.

A close look to all these values shows that there is a large difference between all these dimensions. This specificity leads to meshing problems while modeling such component. Indeed, meshes have to be very thin inside the copper conductors to take into account HF effects, while the mesh's size can be relaxed for the magnetic core. Between PCB and core, meshing has to be extended gradually, particularly in corners of PCB rectangular conductors. As a consequence, with such 3-D meshing, the number of unknows will increase exponentially and will lead to huge numerical problems to be solved.

\subsection{Impact of Meshing}

Meshing, i.e. the numerical modeling spatial discretization, is a key point to solve a finite element (FE) problem. In order to obtain valid FE simulations in wide frequency range, meshing has to be densified in areas where fields' variations $(\mathbf{E}, \mathbf{B})$ are important.

Let's take the example of an infinite plate (Fig.2). The current density distribution is linked to equation (1) and the field $(\mathbf{H})$ is tangential to the plate. Then, the volumic current density is one dimensional $\mathbf{J}(x, y, z, t)=\mathbf{J}(x, t)$ (2). The evolution of the envelope of $\mathbf{J}$ at $t=0$ is presented on Fig.2 to highlight the effect of spatial discretization. 
Table 1 Planar Ferrite Typical Lengths (Data from [30])

\begin{tabular}{c|c|c|c|c|c}
\hline Core & $w_{c}$ & $h_{c}$ & $d_{c}$ & $w_{w}$ & $h_{w}$ \\
\hline & $(\mathrm{mm})$ & $(\mathrm{mm})$ & $(\mathrm{mm})$ & $(\mathrm{mm})$ & $(\mathrm{mm})$ \\
\hline$E E 14 / 3.5 / 5$ & 14 & 7 & 5 & 4 & 4 \\
$E E 18 / 4 / 10$ & 18 & 8 & 10 & 5 & 4 \\
$E E 22 / 6 / 16$ & 22 & 11.4 & 15.8 & 5.9 & 6.4 \\
$E E 32 / 6 / 20$ & 31.75 & 12.7 & 20.3 & 9.27 & 6.36 \\
$E E 38 / 8 / 25$ & 38.1 & 16.52 & 25.4 & 11.31 & 8.9 \\
$E E 43 / 10 / 28$ & 43.2 & 19 & 27.9 & 13.3 & 10.8 \\
$E E 58 / 11 / 38$ & 58.4 & 21 & 38.1 & 20.95 & 13 \\
$E E 64 / 10 / 50$ & 64 & 20.4 & 50.8 & 21.8 & 10.2 \\
\hline
\end{tabular}

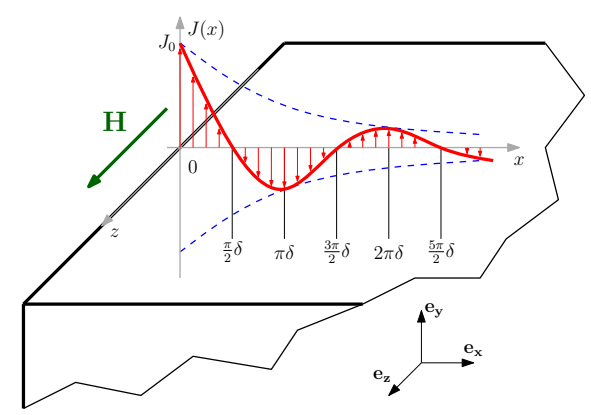

Fig. 2. Volumic current density diffusion inside an infinite plate

$$
\Delta \mathbf{J}=\mu \sigma \frac{\partial \mathbf{J}}{\partial t}
$$

where $\mu$ and $\sigma$ are the permeability and the conductivity of the material, respectively.

$$
\mathbf{J}(x, t)=J_{0} \cdot e^{-\frac{x}{\delta}} \cos \left(\omega t-\frac{x}{\delta}\right) \mathbf{e}_{\mathbf{y}}
$$

where $\delta(3)$ is the skin depth.

$$
\delta=\sqrt{\frac{1}{\pi \sigma f \mu}}
$$

where $f$ is the frequency.

In order to facilitate the interpretation of the skin effect, also known as the Kelvin effect, the concept of "fictive shell" (Fig.3(a)) is proposed in [31]. At the energetic level, it is as if $\mathbf{J}$ flows through a thickness $\delta(3)$ where $\forall x \in[0, \delta],|\mathbf{J}(x)|=J_{0} / \sqrt{2}$. Indeed, the power density $P_{s}$ is equivalent with both distributions (4) (5). However, the current density distribution is continuous and significant on thicknesses of many $\delta$.

$$
\begin{gathered}
P_{s}=\int_{0}^{\infty} \rho \mathbf{J}^{2}(x) d x=\rho \int_{0}^{\infty} \mathbf{J}^{2}(x) d x \\
\int_{0}^{\infty}\left(J_{0}\right)^{2} e^{-\frac{2 x}{\delta}}=\int_{0}^{\delta} \frac{\left(J_{0}\right)^{2}}{2} d x=\frac{J_{0}^{2} \delta}{2}
\end{gathered}
$$



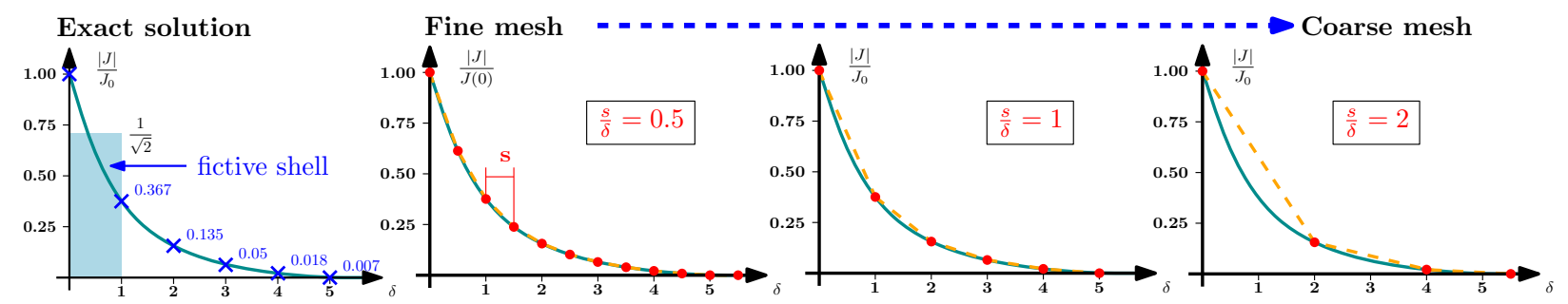

(a)

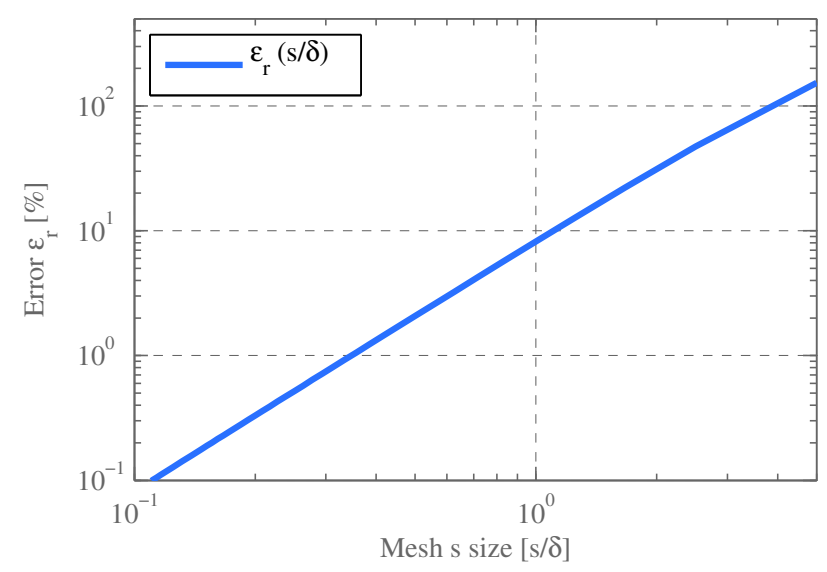

(b)

Fig. 3. Impact of meshing

a Computation of $\mathbf{J}$ with different mesh size

b Error $\epsilon_{r}$ due to mesh's size $\left(\frac{s}{\delta}\right)$

Table 2 Skin depths and minimal mesh size for copper conductors at $300^{\circ} \mathrm{K}$

\begin{tabular}{c|c|c|c|c|c}
\hline Frequency $(k H z)$ & 1 & 10 & 100 & $10^{3}$ & $10^{4}$ \\
$\delta(\mu m)$ & 2075 & 656 & 207 & 65.6 & 20.7 \\
Maximum mesh size for a 1\% error $(\mu m)$ & 691 & 218 & 69 & 21 & 6.9 \\
\hline
\end{tabular}

The Fig.3(a) highlights the impact of a coarse mesh on the computation of J. On this figure, $s$ is the space between two nodes of the mesh. $\mathbf{J}$ is supposed to be well calculated on these nodes and intermediate points are determined based on linear interpolation. Error, $\epsilon_{r}\left(P_{C u}^{r e f}, P_{C u}^{\frac{s}{\delta}}\right)$, between the exact solution of copper loss calculation $\left(P_{\mathrm{Cu}}^{r e f}\right)$ and the one obtained with different mesh's size $\left(P_{C u}^{\frac{s}{\delta}}\right)$ is plotted on Fig.3(b). To obtain a computation's error below 1\%, it appears that 3 meshes have to be included in the skin depth (3), at least. The table 2 lists some skin depth values and their associated maximum mesh value.

\subsection{Finite Element Problem to be Solved}

PMC are made of three different materials: electrical conductor (copper), magnetic conductor (ferrite) and insulating material (FR4, or Kapton for example) for PCB (Fig.1(d)).

To calculate HF impedances, full Maxwell's equations [32] have to be solved taking into account the permittivity of the PCB. For the frequency below $10 \mathrm{MHz}$, the finite element problem can be reduced to a time harmonic eddy current problem (6) (7) (8). In this case, the insulating 


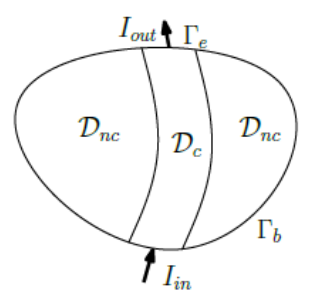

Fig. 4. FE problem

material is considerated as a nonconducting material. The magnetic material is also considerated as nonconducting material. Only the PCB's copper tracks are modeled as conducting material. In these conditions, there are only two subdomains (Fig.4): conductor domain $\mathcal{D}_{c}$ and non-conductor one $\mathcal{D}_{n c}$. The boundary of the domain is denoted by $\Gamma=\Gamma_{b} \cup \Gamma_{e}$.

$$
\begin{gathered}
\operatorname{rot} \mathbf{E}=-j w \mathbf{B} \\
\operatorname{rot} \mathbf{H}=\mathbf{J}_{s}+\mathbf{J}_{e d} \\
\operatorname{div} \mathbf{B}=0
\end{gathered}
$$

where $\mathbf{E}, \mathbf{H}$ and $\mathbf{B}$ are the electrical field, the magnetic field and the magnetic flux density, respectively. The current density vector (7) can be divided in two terms : one source $\left(\mathbf{J}_{s}\right)$ and one induced $\left(\mathbf{J}_{e d}\right)$. The boundary conditions are given by :

$$
\begin{gathered}
\mathbf{E} \wedge \mathbf{n}=\left.\mathbf{0}\right|_{\Gamma_{e}} \\
\mathbf{B} . \mathbf{n}=\left.0\right|_{\Gamma_{b}}
\end{gathered}
$$

In this paper, the eddy current problem is solved with potential formulation $(\mathbf{T}, \Omega)$ [33]. To take into account the current $\mathbf{I}$, the vector potential $\mathbf{K}$ and $N$ are introduced such as

$$
\begin{aligned}
\operatorname{rotK} & =\mathbf{N} \\
\int_{\Gamma_{e}} \mathbf{N} d \mathbf{s} & =1 \\
\operatorname{div} \mathbf{N} & =0 \text { in } \mathcal{D}_{c}
\end{aligned}
$$

Consequently, one can write

$$
\mathbf{J}=\mathbf{J}_{s}+\mathbf{J}_{e d}=\operatorname{rot}(\mathbf{K} I+\mathbf{T}) \text { and } \mathbf{H}=\mathbf{K} I+\mathbf{T}+\operatorname{grad} \Omega
$$

Then the $(\mathbf{T}, \Omega)$ formulation takes the following form

$$
\left\{\begin{aligned}
\operatorname{rot} \frac{1}{\sigma} \operatorname{rot}(\mathbf{K} I+\mathbf{T})+j \omega \mu(\mathbf{K} I+\mathbf{T}+\operatorname{grad} \Omega) & =\mathbf{0} \text { in } \mathcal{D}_{c} \\
\operatorname{div} \mu(\mathbf{K} I+\mathbf{T}+\operatorname{grad} \Omega) & =\mathbf{0} \text { in } \mathcal{D}_{n c}
\end{aligned}\right.
$$

with $\sigma$ the electrical conductivity and $\mu$ the magnetic permeability. In our case $I$ is fixed.

The FE formulation is solved using code_Carmel3D [34]. This FE code was first developed for low frequency electrotechnical machines. For HF magnetic components, code_Carmel3D presents some advantages: 
1. Both FE formulations $(\mathbf{T}, \Omega)$ and $(\mathbf{A}, \Phi)$ can be used even if the $(\mathbf{A}, \Phi)$ one is unusable with small mesh $(<0.1 \mathrm{~mm})$.

2. code_Carmel3D presents high performances in terms of number of unknows (some Millions).

3. The FE code is open and can be used for reduced order model [35], useful for faster computations.

As a major drawback, the meshing has to be very thin in HF, as well as in other commercial codes [29].

\section{Modeling of Planar inductors}

In this section, FEA is performed on 2D and 3D numerical models of planar components. Results are compared in terms of copper losses and current densities. Two types of devices are modeled:

- "PCB": For these devices, only windings of planar magnetics are modeled. PCB windings with 2-turns, 4-turns and 8-turns, splitted on 2-layers, are simulated in 2D and 3D. As an example, the 3D model of the 4-turn PCB is presented in Fig.6(a).

- "Inductor": Planar inductors are modeled including PCB winding combined with lossless magnetic core. Examples are given in Fig.5 for the 2D model and in Fig.6(c) for the 3D one.

\subsection{Components' Description}

As mentioned before, PCB are made of 2, 4 and 8 turns on 2 layers of thickness $h_{t}=35 \mu m$. For each case, conductor's width $\left(w_{t}\right)$ is $7 \mathrm{~mm}, 3 \mathrm{~mm}$ and $1.5 \mathrm{~mm}$ respectively. The three inductors are based on the use of these PCB for windings and a double E32/6/20 3F3 ferrite magnetic core [30], whose dimensions are given in Table 1. All these devices are used to study the impact of geometry on copper loss distribution. The lenghts were set to present large discrepancy between minimal and maximal dimensions as well as element's size for the mesh.

For the numerical computation of HF copper losses, some simplifications are done:

1. Electromagnetic behavior of the epoxy FR4 (Fig.1(d) from PCB is not taken into account $\left(\mu_{r}=1\right)$. Therefore, Epoxy is not modeled in FEA simulations.

2. Capacitive effects between conductors are not considered. FEA is only performed to focus on copper losses in a frequency range where the device will be used, including main harmonics. These parasitic capacitive effects between copper tracks and between copper and ferrite core appear for higher frequency. This topic is not in the scope of this study.

3. $3 F 3$ Ferrite magnetic material is supposed lossless and its permeability is constant $\left(\mu_{r}=\right.$ 2000). The ferrite core modify magnetic field around copper conductors and then copper losses. If magnetic core losses were considered in the FEA, it will be difficult to separate both types of losses in particular during the experimental validation stage. The inductance value an its variation with frequency is not either in the scope of this work.

\subsection{D Modeling}

Only winding windows are modeled for these 2D simulations. For PCB device, only the copper tracks are modeled while for inductors, the PCB windings are included in a ferrite core. Conductor 

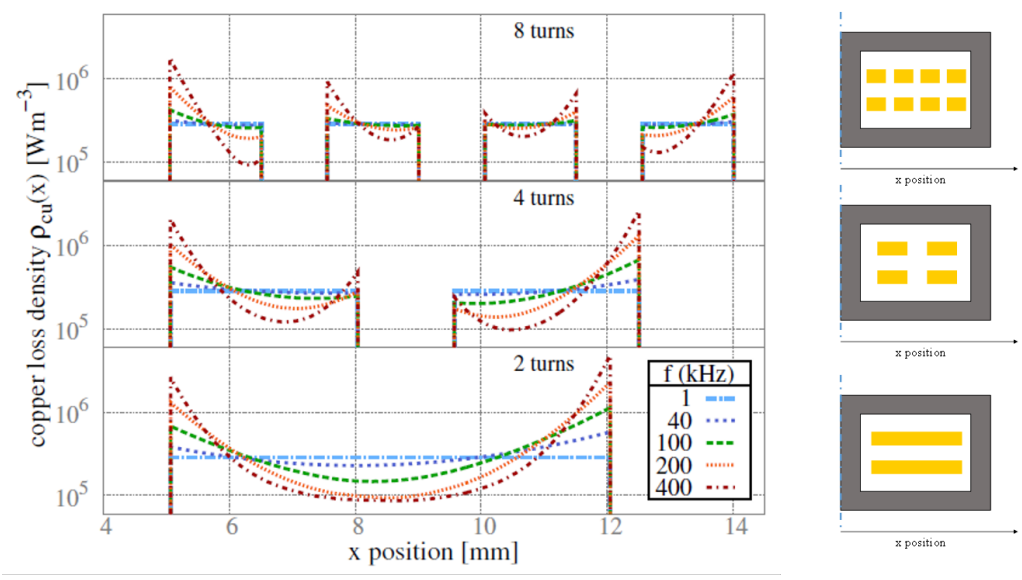

Fig. 5. Copper loss density computed with 2D FEA as a function of frequency for the 3 planar magnetic inductors.

Copper loss densities (15) in the three inductors are presented in Fig.5. Note that the evolution of losses with the frequency is different for the three models. Indeed, because of skin and proximity effects, the current is concentrated at the ends of the conductors. This effect varies according to the ratio of the width of the conductor $w_{t}$ (Fig.1(d)) on the skin thickness (3).

Thus, the planar inductor of 8 turns with $w_{t}=1.5 \mathrm{~mm}$ has a better HF behavior than the 2 turns one with $w_{t}=7 \mathrm{~mm}$. The use of 2D simulations presents real benefits in terms of computations but needs to have homogenous losses (i.e. same current density on the tracks's lenghts) inside the component to be relevant.

$$
\rho_{c u}=\mathbf{J} \cdot \mathbf{E}
$$

\subsection{D Modeling}

For 3D FEA, the PCB and inductors under simulation are enclosed in an air cubic box of length $10 \mathrm{~cm}$. The magnetic field $\mathbf{H}$ is tangential to the outer surfaces of the box. A current of $1 A_{r m s}$ value flows through the copper tracks and a very fine mesh of conductors is used to simulate the resistance variations in $\mathrm{HF}$ (until $30 \mathrm{MHz}$ ). As an example, the number of FE unknowns reaches 1.9 Million (with the use of 40 Go RAM) for $14 \mu m$ meshes inside the conductors of the 2-turn inductor.

First, only copper layers on PCB are modeled. Such application, without magnetic core, can be interesting for contactless energy transfer [36], HF drivers [37], bendable transformer [38] or very high frequency (VHF) transformer for example [39]. Fig. 6(a) presents copper loss density distribution for the 4-turn PCB without core. Results are presented for $10 \mathrm{kHz}, 100 \mathrm{kHz}$ and $1 \mathrm{MHz}$, respectively. The $2 \mathrm{D}$ simulation loss homogenization hypothesis is verified for low frequency (LF) $10 \mathrm{kHz}$ and $100 \mathrm{kHz}$ (Fig. 6(a)). Indeed, the copper loss density plotted on a cross section perpendicular to the current flow direction is identical all along the copper tracks. The Fig.6(b) presents these areas where this hypothesis is valid. It can be noted that in the copper track corners, the geometry is different and hence the copper loss density.

For $1 \mathrm{MHz}$, a current concentration is observed on the extremity of copper layers (Fig. 6(a)). That concentration in the PCB ends leads to an increase of the copper losses. Copper loss density 
is also stronger in the PCB corners. The area where the 2D simulation loss homogenization hypothesis is valid is limited to the PCB central part (Fig.6(b)). 2D simulations will only give correct losses on approximately $25 \%$ of the 4-layer PCB.

Then, the ideal planar magnetic core is added to the PCB. Copper loss density repartition, obtained at $1 \mathrm{MHz}$, is shown in Fig.6(c) for the 3 inductors with 2, 4 and 8 turns, respectively. A current concentration on the conductors' edge can be observed, as in the previous case without magnetic core. However, the losses distribution along the inductor is more homogeneous. Considering the copper tracks under the magnetic core, 2D simulations can give correct losses estimation on $50 \%$ of the whole component (Fig.6(d)).

A local study enables to understand differences between 2D and 3D FEM simulations. Indeed, a close look at the current density vector field (Fig.7) allows highlighting the origin the HF losses in windings' ends. For the 4-turn PCB case (Fig.7(a)), the proximity effect between turns involves the emergence of current loops. A current flowing in the opposite direction is created on a large part of the inner conductors. This effect appears only when the conductors width is large enough compared to the skin depth (3). This phenomenon changes loss distribution and thus increase the copper losses. As a comparison, the current density vector field for the 4-turn inductor is shown in Fig.7(b). Current loops are less important than for the case of the PCB alone. A current is still flowing in the opposite direction but its proportion is much lower. This effect is greater on the copper tracks outside the magnetic core. Under the core, the magnetic flux generated by a turn is concentrated in the magnetic material and have less impact on other close conductors. The 2D loss homogenization hypothesis is consistent inside the magnetic core's winding. Without core, the copper loss density varies with the third dimension.

\section{Comparison and Analysis}

In the previous section, 2D and 3D FEM simulations were performed for PCB and inductors with 2, 4 and 8 turns. Results are now compared together to deduce rules of 2D and 3D FEA usage.

\subsection{Overall Analysis: Resistive Factor Comparison}

The global comparison of 2D and 3D modeling results is made based on the relative resistance factor $F_{r}$ (16). This factor, applied to copper windings, allows quantifying the increase of resistance with frequency. The relative error $\epsilon_{r}$ is also calculated to quantify the difference between simulations results and measurements.

$$
F_{r}(f)=\frac{R_{A C}(f)}{R_{D C}}
$$

4.1.1. PCB: In order to compare FEA simulation results, impedance measurements are performed on a 4-turn 2-layer PCB. These measurements are achieved using impedance analyzer HP4294 [40]. Resistance values are plotted on a large frequency range, from $1 \mathrm{kHz}$ to $30 \mathrm{M} \mathrm{Hz}$. The Fig.8(a) presents the 4-turn PCB relative resistance factors for 2D, 3D FEA results and prototype's measurements. The relative errors $\varepsilon_{r}$ are plotted in Fig.8(b). 2D simulations underestimate the resistance between $100 \mathrm{kHz}$ and $30 \mathrm{MHz}$. The resistance value and thus the copper looses are calculated with $10 \%$ error. The difference between simulation results and measurements for frequency higher than $5 \mathrm{MHz}$ can be explained by two main reasons:

1. The parasitic capacitance $C_{p}$ that exists between the two PCB layers leads to a resonance with 


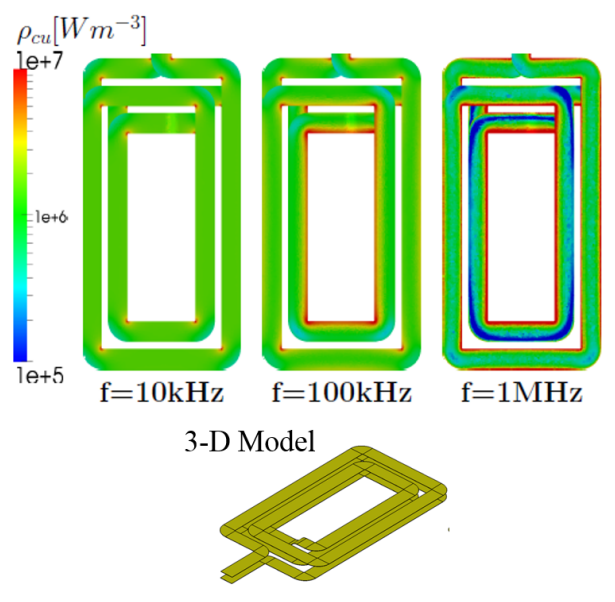

(a)

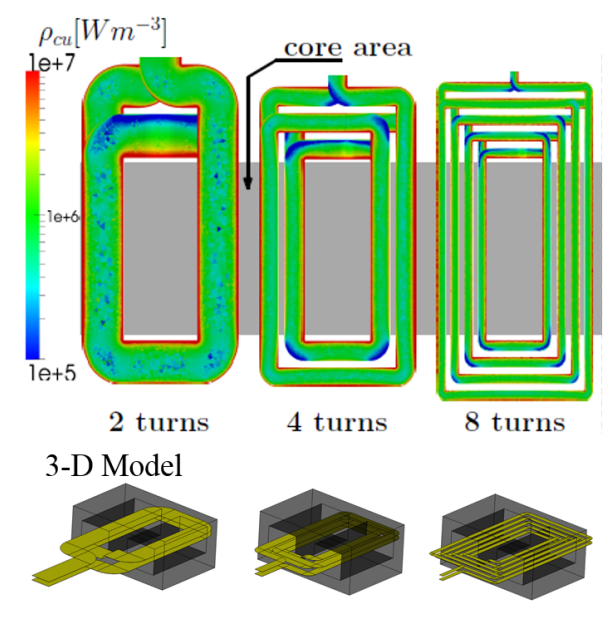

(c)

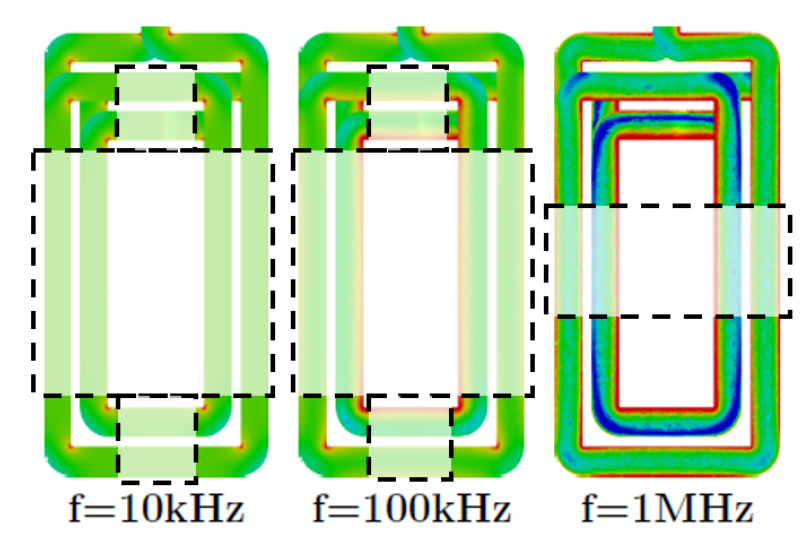

(b)

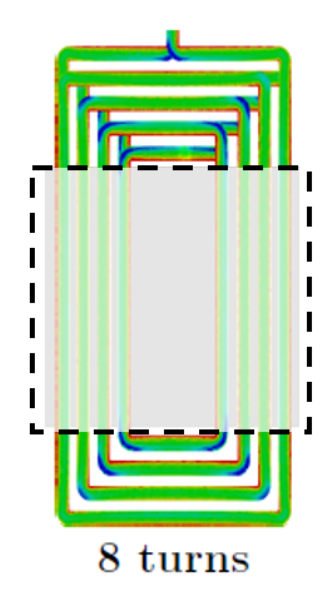

(d)

Fig. 6. Copper loss density repartition

a 4-turn PCB without ferrite core. Impact of frequency $(10 \mathrm{kHz}, 100 \mathrm{kHz}$ and $1 \mathrm{M} \mathrm{Hz})$

b Areas for the 2D simulation loss hypothesis - PCB w/o magnetic core

c Inductors at $1 \mathrm{MHz}$. Impact of turn number ( 2 turns, 4 turns and 8 turns)

$\mathrm{d}$ Area for the 2D simulation loss hypothesis - 8-turn inductor w/ magnetic core 


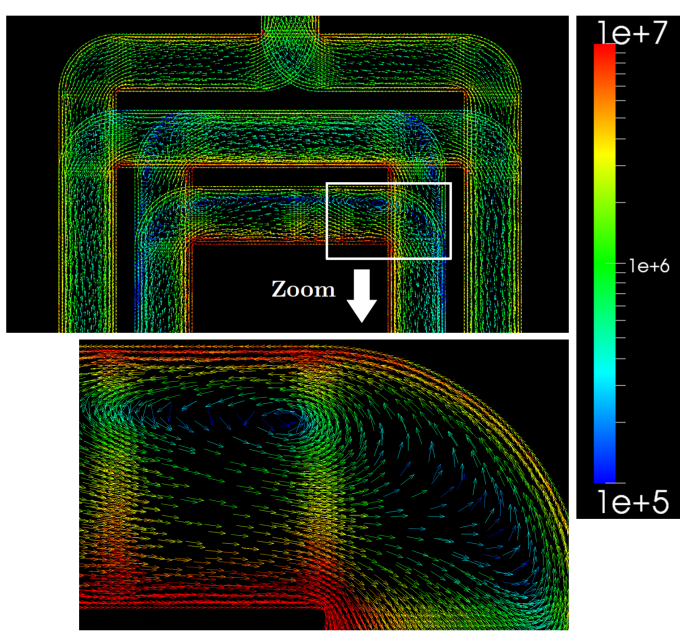

(a)

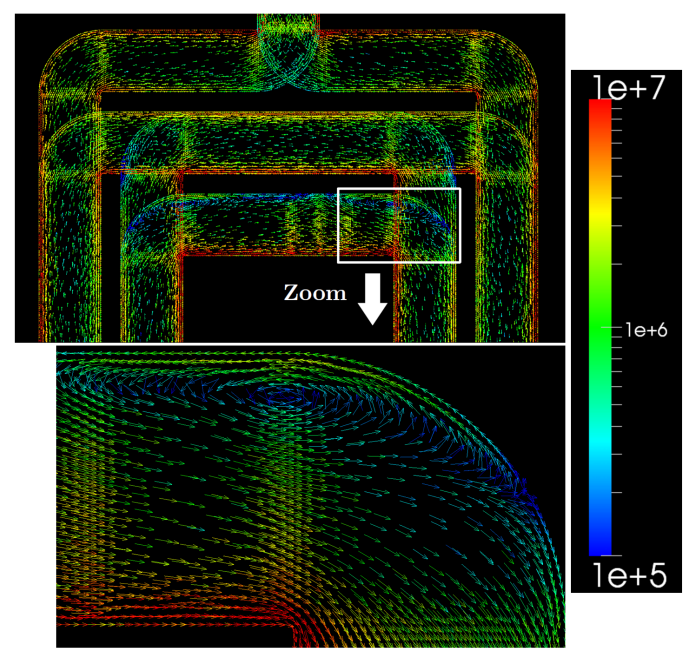

(b)

Fig. 7. Current density vector field at $1 \mathrm{MHz}$

a PCB w/o magnetic core

b Inductor w/ magnetic core

the inductor close to $80 \mathrm{MHz}$. The measurement validity range is then limited to $8 \mathrm{MHz}$. For higher frequency, $C_{p}$ increases the measured resistance. This phenomenon can explain the relative errors higher than $20 \%$ for frequency above $10 \mathrm{MHz}$ (Fig.8(b)).

2. Meshing is also a source of errors. Indeed, for 3D simulations, meshes are set to $60 \mu \mathrm{m}$ while for $2 \mathrm{D}$ ones, meshes are 6 times thinner (about $10 \mu \mathrm{m}$ ). As a consequence, the 3-D simulation is also underestimated from $8 \mathrm{MHz}$.

4.1.2. Planar Inductors: Regarding inductors, measurements with ferrite magnetic core, can not be compared to FEA simulations results. Indeed, simulations were performed using ideal lossless magnetic core to highlight the modeling impact on copper losses. Resistance measurements on a planar inductor will be hidden by the influence of the ferrite losses in HF. The copper winding relative resistances obtained for $2 \mathrm{D}$ and $3 \mathrm{D}$ simulations are compared in Fig.8(c). The difference between both modeling approaches is included in the range $[5 \%-10 \%]$ until $4 \mathrm{MHz}$ (Fig.8(d)). A significant error appears for higher frequency. The 3D inductor modeling presents same limitations than for the PCB alone.

\subsection{Variation of copper losses along PCB conductors}

The main hypothesis, that enables the use of 2D simulations to obtain precisely losses, is the homogeneous losses inside the component. That means that the current density and the copper losses are quite similar and do not vary all along the component's track. In order to validate this hypothesis, 3D simulation are performed to locally analysed variations of current density along PCB conductors.

4.2.1. Conductor's width: x-axis: The change of losses is now studied as a function of the layer's width. The copper losses density $\rho_{c u}$ range of variation is plotted as a function of $x$ for the PCB on Fig.9(a) and for the inductor with magnetic core on Fig.9(b). On these figures, the 


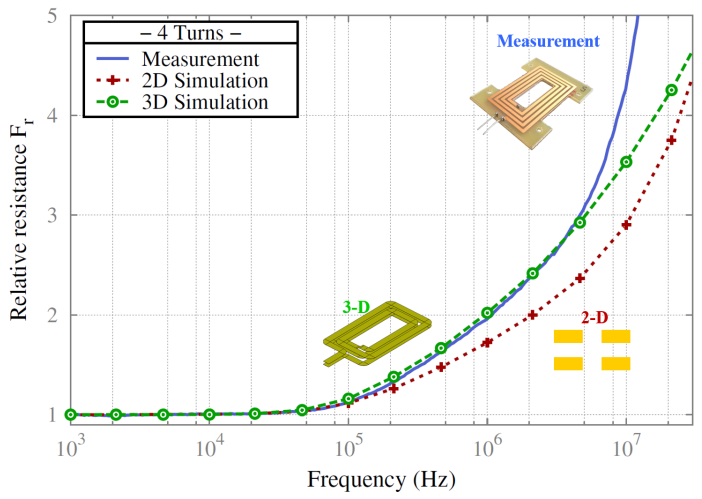

(a)

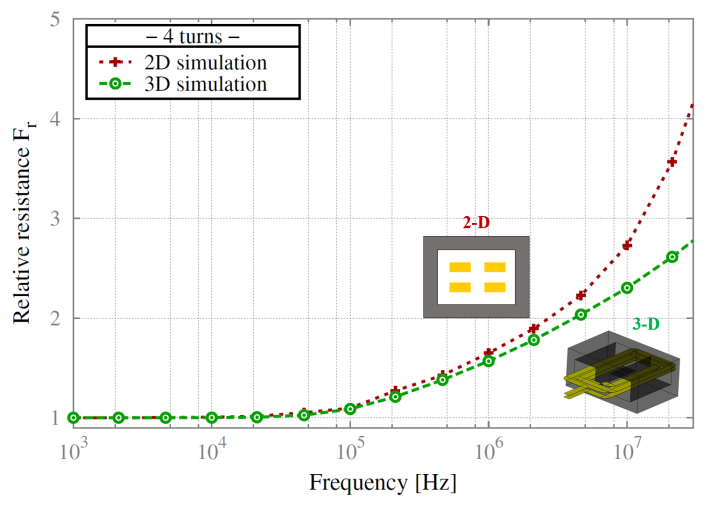

(c)

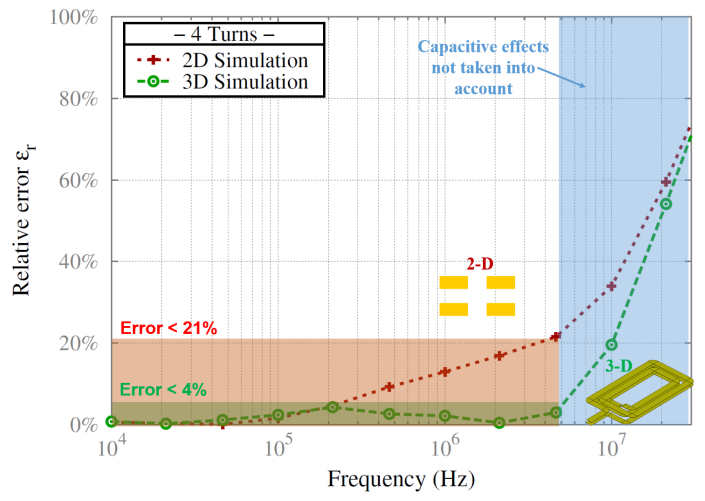

(b)

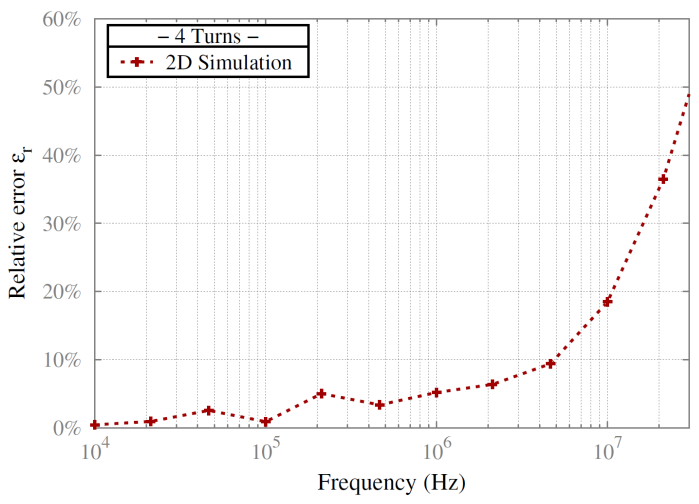

(d)

Fig. 8. Copper winding relative resistance versus frequency a Comparison between 2D, 3D and measurement for the 4-turn PCB b Relative error compared to measurement for the 4-turn PCB c Comparison between 2D and 3D for the 4-turn inductor $\mathrm{d}$ Relative error for the 4-turn inductor 
coordinates center corresponds to the center of the device.

The evolution of $\rho_{c u}$ is calculated according to $y$ values with a fixed $z$. The obtained values create a curve network that is plotted on Fig.9(a) for the 4-turn PCB and on Fig.9(b) for the 4turn inductor. The variation's band and the average value are also plotted in these figures. These curves enable to compare 2-D and 3-D modeling. Indeed, the curve network area depicts effects of 3-D modeling. Moreover, the average value $\left\langle\rho_{c u}\left(x, y, z_{0}\right)\right\rangle_{y}$ (17) enables to directly compare results from 2D and 3D modeling. The range of variation for $y$ is shown on Fig.9(a) and Fig.9(b). The average distribution along the $\mathrm{x}$-axis is also presented, as well as the $2 \mathrm{D}$ simulation results. It should be noted that the $2 \mathrm{D}$ meshing is finer than in the case of $3 \mathrm{D}$ simulations because of computing memory limitations. This difference between both meshes can explain the obtained curves.

For the 4-turn PCB (Fig.9(a)), one can note that losses seem fairly accurate on the inner edge $(x=5.1)$ and the outer one $(x=12.1)$. Difference between average value $\rho_{c u}$ and $2 \mathrm{D}$ modeling results is more significant for $x=8.1$ and $x=9.1$.

For the 4-turn inductor with magnetic core (Fig.9(b)), the 3-D average value is very close to the $2 \mathrm{D}$ one. The magnetic material enables to minimize variation along the copper conductor.

$$
\left\langle\rho_{c u}\left(x, y, z_{0}\right)\right\rangle_{y}=\int_{y_{\min }}^{y_{\max }} \rho_{c u}\left(x, y, z_{0}\right) d y
$$

with $z_{0}$ located at the upper layer center.

4.2.2. Conductor's length: $y$-axis: In order to quantify the differences between $2 \mathrm{D}$ and $3 \mathrm{D}$ modeling, copper loss average density $\left\langle\rho_{c u}\left(x, y, z_{0}\right)\right\rangle_{x}(18)$ is calculated along conductor length in the $y$ direction. The ratio $\rho_{c u 3 D} / \rho_{c u 2 D}$ is then obtained and shown in Fig.9(c) for 2, 4 and 8 turns PCB and in Fig.9(d) for the inductor at $1 M H z$.

For the PCB without core (Fig.9(c)), 2D modeling provides a good loss estimation on the range $y \in[-5 \mathrm{~mm}: 5 \mathrm{~mm}]$. Outside this interval, edge effects increase differences between both modeling until an error of $50 \%$. Fluctuation of $\left\langle\rho_{c u}\right\rangle_{x}$ is due to the mesh.

With the ferrite magnetic core (Fig.9(d)), 2D simulations overestimate losses about $4.6 \%$ on the interval $y \in[-10 \mathrm{~mm}: 13 \mathrm{~mm}]$. Outside this range, edge effects are increased and the obtained error with the $2 \mathrm{D}$ simulation is close to $10 \%$. In such case, the homogeneous loss hypothesis appears to be more credible with magnetic core than the case without.

$$
\left\langle\rho_{c u}\left(x, y, z_{0}\right)\right\rangle_{x}=\int_{x=5.1}^{x=12.1} \rho_{c u}\left(x, y, z_{0}\right) d x
$$

\subsection{Discussion}

In order to answer the three main questions, some results analysis can be discussed. Some conclusions are summarized below:

1. The increase of power electronics switching frequency leads to the use of numerical tools to correctly model planar components. Indeed, the hypothesis, traditionally made for analytical calculations, cannot be applied for such geometry and operating frequency.

2. 3D modeling of PCB enables to compute copper losses precisely $\left(\epsilon_{r}<5 \%\right.$ for $\left.f<6 M H z\right)$. Same computation with 2D models can reach more than $21 \%$ at $5 \mathrm{MHz}$. 


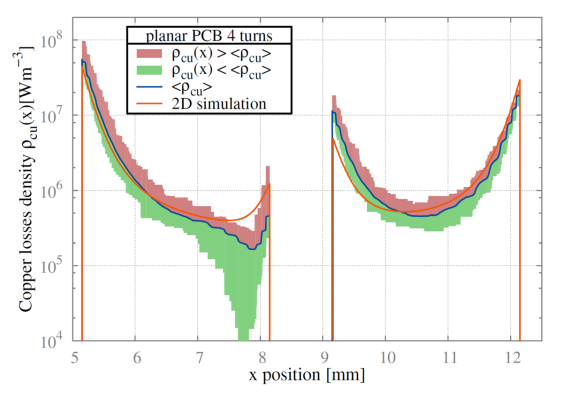

(a)

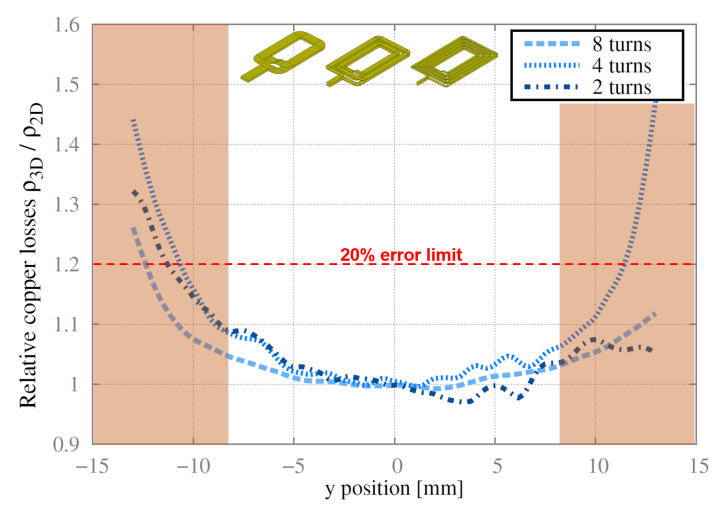

(c)
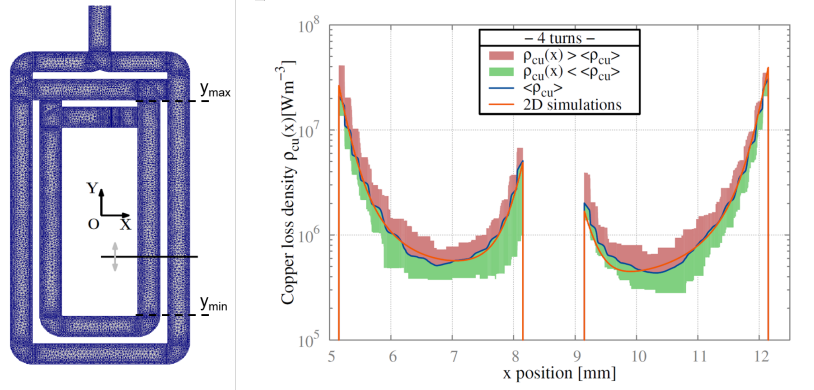

(b)
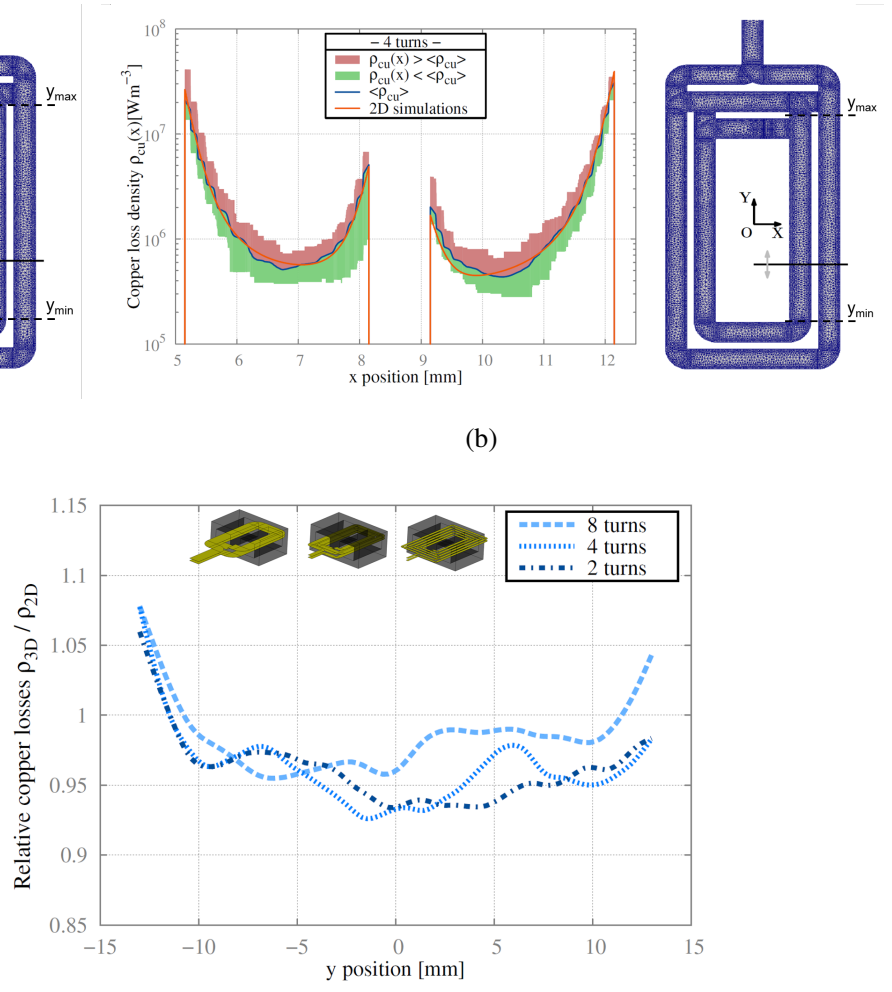

(d)

Fig. 9. Distribution of copper losses

a Copper losses density as a function of $\mathrm{x}$ for the 4-turn 2-layer PCB w/o magnetic core at $1 \mathrm{MHz}$ $\mathrm{b}$ Copper losses density as a function of $\mathrm{x}$ for the 4-turn 2-layer inductor $\mathrm{w} /$ magnetic core at $1 \mathrm{MHz}$ c Relative copper losses as a function of y for a 2, 4 and 8-turn PCB w/o magnetic core at $1 \mathrm{MHz}$ d Relative copper losses as a function of y for a 2, 4 and 8-turn inductor w/ magnetic core at $1 \mathrm{MHz}$ 
3. When a magnetic material is used, the differences between $2 \mathrm{D}$ and $3 \mathrm{D}$ simulations stay below $5 \%$.

As a consequence, it seems necessary to model in 3D when the component does not contain magnetic material. Indeed, regarding components with magnetic core, the homogeneous loss hypothesis appears to be interesting and 2D modeling enables to obtain quite good approximation of copper losses. This conclusion is valid for traditional PCB and copper foil planar transformer. For less classical design [41], 3D approach will always be necessary as well as for local studies of losses inside windings [42]. 3D modeling seems also useful when studying impact of harmonics. Indeed with 2D, losses are underestimated for high frequency. Moreover, when frequency is too high, magnetic core might lose its properties. Then, 3D seems essential.

In this study, conditions applied to numerical simulations and impedance measurements are quite restrictive. Indeed, simulations were performed with pure sinus voltage and current. The same goes for impedance measurements, in low signal. Obviously, in a power converter, magnetic components are not supplied with pure sinus low voltage but with large signals containing HF harmonics. Furthermore, PE magnetic components are source of magnetic losses and other HF parasistic effect like capacitances for example. It could be interesting to perform FEA and measurements under real operating conditions to test validity of numerical models, including all these effects. Such simulation, in time-domain, is very complicated, time-consuming and necessits accurate models of material to be compared to measurements. From the practical point of view, even these measurements are difficult and needs specific appliance and tests to separate copper losses and magnetic material ones [43]. Consequently, for these reasons, a frequency-domain analysis at harmonic values is usually prefered when designing magnetic components. Conclusions of this study are therefore directly applicable by designers.

\section{Conclusion}

Numerical modeling appears as the only alternative to model HF magnetic components, taking into account geometry and material characteristics. In this paper, planar magnetic component copper losses are numerically computed on a large frequency range based on 2D and 3D FEA. Simulations results and performances are compared on PCB and inductor devices. 3D FEA Modeling gives better results with errors lower than $5 \%$ in comparison with measurements on PCB prototype until few Megahertz. The 2D modeling leads to significant errors, close to $10 \%$ from $1 \mathrm{MHz}$. For the inductor, i.e PCB and ferrite magnetic core, the winding outside the magnetic core is the main cause of differences between simulation results. The magnetic field is concentrated in magnetic material and thus limits differences between 2D and 3D simulation. In these cases, 2D models can finally be sufficient difficulties induced by 3D modeling.

\section{References}

[1] Ouyang, Z., Andersen, M. A. E.: 'Overview of Planar Magnetic Technology Fundamental Properties', IEEE Trans. Power Electron., 2014, 29, (9), pp. 4888-4900

[2] Quinn, C. , Rinne, K., O’Donnell, T., Duffy, M., Mathuna, C.O.: 'A review of planar magnetic techniques and technologies', Proc. Applied Power Electronics Conference and Exposition, APEC, 2001, vol.2, pp. 1175-1183 
[3] Ngoua Teu Magambo, J. S., Bakri, R., Margueron, X., Le Moigne, P., Mahe A., Guguen, S., Bensalah, T.: 'Planar Magnetic Components in More Electric Aircraft: Review of Technology and Key Parameters for DC-DC Power Electronic Converter,' IEEE Trans. Transportation Electrification, PP, (99), pp. 1-1

[4] Hurley, W. G., and Wolfle, W. H.: 'Transformers and Inductors for Power Electronics: Theory, Design and Applications', 1st ed. Wiley, 2013.

[5] Water, W., Lu, J.: 'Improved High-Frequency Planar Transformer for Line Level Control (LLC) Resonant Converter', IEEE Magnetics Letters, 2013, 4, pp. 1-4

[6] Ibanez, F., Echeverria, J. M., Fontan, L.:'Novel technique for bidirectional series-resonant DC/DC converter in discontinuous mode', IET Power Electron., 2013, 6, (5), pp. 10191028

[7] Am S., Lefranc P., Frey, D.: 'Design methodology for optimising a high insulation voltage insulated gate bipolar transistor gate driver signal transmission function', IET Power Electron., 2015, 8, (6), pp. 1035-1042.

[8] Chen, R., Wyk, J. V., Wang, S. and Odendaal, W.: 'Improving the Characteristics of integrated EMI filters by embedded conductive Layers', IEEE Trans. Power Electron., 2005, 20, (3), pp. 611619

[9] Tan, W., Margueron, X., Taylor, L., Idir, N.: 'Leakage Inductance Analytical Calculation for Planar Components with Leakage Layers', IEEE Trans. Power Electron., 2016, 31, (6), pp. $4462-4473$

[10] Feng, B., Zhong-xia, N.,Yu-Jie, S., Dong-fang, Z.: 'EMI Modeling and Simulation of High Voltage Planar Transformer', Proc. Power Electronics, Drives and Energy Systems, PEDES, 2006, 12-15 Dec. 2006.

[11] Wang, Y.A., Xiao, D.M.:'Prototype design for a high-voltage high-frequency rectifier transformer for high power use', IET Power Electron., 2011, 4, (6), pp. 615623.

[12] Lefranc P., Odic, E., Kirkpatrick, M. J.:'Optimisation and characterisation of a planar transformer with a high voltage ratio and high output voltage for plasma reactors', IET Power Electron., 2015, 8, (6), pp. 929937.

[13] Margueron, X., Besri, A., Lembeye, Y., Keradec, J-P.: 'Current Sharing Between Parallel Turns of a Planar Transformer: Prediction and Improvement Using a Circuit Simulation Software'," IEEE Trans. Ind. Applications, 2010, 46, (3), pp. 1064-1071

[14] Prieto, R., Oliver, J. A, Cobos, J. A. and Christini, M.: 'Magnetic Component Model for Planar Structures Based on Transmission Lines', IEEE Trans. Ind. Elect., 2010, 57, (5), pp. 1663-1669

[15] Chen, M., Araghchini, M., Afridi, K. K., Lang, J. H., Sullivan C. R. and Perreault, D. J.: 'A Systematic Approach to Modeling Impedances and Current Distribution in Planar Magnetics', IEEE Trans. Power Electron., 2016, 31, (1), pp. 560-580

[16] Tria, L. A. R., Zhang D. and Fletcher, J. E.: 'Implementation of a Nonlinear Planar Magnetics Model', IEEE Trans. Power Electron., 2016, 31, (9), pp. 6534-6542 
[17] Dimitrakakis, G.S., Tatakis, E.C.: 'High-Frequency Copper Losses in Magnetic Components With Layered Windings', IEEE Trans. on Magnetics, 2009, 45, (8), pp. 3187-3199

[18] Reatti, A., Kazimierczuk, M.K.: 'Comparison of various methods for calculating the AC resistance of inductors', IEEE Trans. on Magnetics, 2002, 38, (3), pp. 1512-1518

[19] Chen W., Yan Y., Hu, Y., Lu, Q.: 'Model and Design of PCB Parallel Winding for Planar Transformer', IEEE Trans. Mag., 2003, 39, (5), pp. 3002-3004

[20] Han Y., Eberle, W., Liu, Y-F.: 'A Practical Copper Loss Measurement Method for the Planar Transformer in High-Frequency Switching Converters', IEEE Trans. Ind. Electron., 2007, 54, (4), pp. 2276-2287

[21] Podoltsev, A.D., Kucheryavaya, I.N., Lebedev, B.B.: 'Analysis of effective resistance and eddy-current losses in multiturn winding of high-frequency magnetic components', IEEE Trans. Mag., 2003, 39, (1), pp. 539-548

[22] Wang, N., O'Donnell, T., O'Mathuna, C.: 'An Improved Calculation of Copper Losses in Integrated Power Inductors on Silicon', IEEE Trans. Power Electron., 2013, 28, (8), pp. 36413647

[23] Dowell, P.L.: 'Effects of eddy currents in transformer windings', Electrical Engineers, Proceedings of the Institution of, 1966, 113, (8), pp. 1387-1394

[24] Aime, J., Cogitore, B., Meunier, G., Clavel, E., Marechal, Y.: 'Numerical Methods for Eddy Currents Modeling of Planar Transformers', IEEE Trans. Mag., 2011, 47, (5), pp. 1014-1017

[25] Prieto, R., Cobos, J. A., Garcia, O., Alou, P., Uceda, J.: 'Study of 3-D magnetic components by means of "double 2-D" methodology", IEEE Trans. Ind. Elec., 2003, 50, (1), pp. 183-192

[26] Ruehli, A.E.: 'Equivalent Circuit Models for Three-Dimensional Multiconductor Systems', IEEE Trans. on Microwave Theory and Techniques, 1974, 22, (3), pp. 216-221

[27] Ngoc, H.B., Chazal, H., Lembeye, Y., Keradec, J.P., Schanen, J.L.: 'New PEEC formulation for modeling 2D core, transformer. Principles, academic and industrial applications', Proc. APEC, 2013.

[28] Kovacevic, I.F., Friedli, T., Musing, A.M., Kolar, J.W.: 'Full PEEC Modeling of EMI Filter Inductors in the Frequency Domain, Magnetics', IEEE Trans. on Magnetics, 2013, 49, (10), pp. 5248-5256.

[29] Roßkopf, A., Br, E., Joffe, C. and Bonse, C.: 'Calculation of Power Losses in Litz Wire Systems by Coupling FEM and PEEC Method', IEEE Trans. Power Electron., 2016, 31, (9), pp. 6442-6449

[30] Ferroxcube. Taipei, Taiwan. Soft Ferrites and Accessories 2008 Sep. [Online]. Available: http://www.ferroxcube.com 'Soft Ferrites and Accessories Data Handbook 2013', http://www.ferroxcube.com/FerroxcubeCorporateReception/datasheet/, accessed june 2017

[31] Boucherot, P.: 'Effet de peau', Bull, S.I.E., 4, 1905.

[32] Bossavit, A.: 'Computational Electromagnetism', Academic Press, Boston, 1998. 
[33] Ren, Z., Razek, A.: 'Comparison of some 3D eddy current formulations in dual systems', IEEE Trans. on Magnetics, 2000, 36, (4), pp. 751-755

[34] 'code_Carmel3D', http://code-carmel.univ-lille1.fr/, accessed june 2017

[35] Taylor, L., Henneron, T., Margueron, X., Le Menach, Y., Le Moigne, P.: 'Model-Order Reduction of Magneto-harmonic Problems Based on POD. Application to Planar Magnetic Components', Eur. Phys. J. Appl. Phys., 2016, 74, (1), 10903

[36] Cove, S. R., Ordonez, M., Shafiei, N. and Zhu, J.: 'Improving Wireless Power Transfer Efficiency Using Hollow Windings With Track-Width-Ratio', IEEE Trans. Power Electron., 2016, 31, (9), pp. 6524-6533

[37] Koudra, F.: 'Design of a driver for Thyristors Using a New Extra Flat Planar Transformer Without Magnetic Circuit', EPE Journal, 2009, 19, (2), pp. 11-19

[38] Ho, G. K. Y., Zhang, C., Pong, B. M. H. and Hui, S. Y. R.: 'Modeling and Analysis of the Bendable Transformer', IEEE Trans. Power Electron., 2016, 31, (9), pp. 6450-6460

[39] Sepahvand, A., Zhang, Y. and Maksimović, D.: '100 MHz isolated DC-DC resonant converter using spiral planar PCB transformer', Proc. IEEE 16th Workshop on Control and Modeling for Power Electronics (COMPEL), 2015, Vancouver, BC, pp. 1-8

[40] 'Agilent 4294A Precision Impedance Analyser-Operation Manual', Agilent Technologies, Santa Clara, CA, USA, 2008.

[41] Djuric, S., Stojanovic, G., Damnjanovic, M., Radovanovic, M. and Laboure, E.: 'Design, Modeling, and Analysis of a Compact Planar Transformer', IEEE Trans. on Magnetics, 2012, 48, (11), pp. 4135-4138

[42] Ngoua Teu Magambo, J. S., Bakri, R., Margueron, X., Le Moigne, P., Mahe, A., Bensalah, T.: 'Impact of PCB Track Shape on HF Copper Losses of Planar Magnetic Components', Proc. International Symposium on Power Electronics, Electrical Drives, Automation and Motion (SPEEDAM), 2016, pp. 973-978

[43] Keradec, J. P., 'Validating the power loss model of a transformer by measurement - Validation is key', IEEE Industry Applications Magazine, 2007, 13, (4), pp. 42-48 